\title{
Abdominal Epilepsy Misdiagnosed as Peptic Ulcer Pain
}

Sir,

We report a rare case of a child with abdominal epilepsy, who had suffered from recurrent episodic abdominal pain ${ }^{1}$ and cyclic vomiting for 3 years misdiagnosed as 'acid peptic disease'. Clues to diagnosis were autonomic phenomena like palpitations, sweating and vomiting during the episode of crampy abdominal pain followed by postictal drowsiness. An abnormal electroencephalogram and a remarkable response to anticonvulsants clinched the diagnosis.

A 9-year-old boy was brought to us 10 months ago with a history of recurrent, paroxysmal abdominal pain and cyclic vomiting for 3 years. Initially these pain attacks occurred once in 3 months but for the past 8 months he was having attacks almost every fortnight. He was labelled as having an acid peptic disorder but despite antiulcer therapy, his pain, frequency and severity had increased. His physical examination, blood counts, blood chemistry, ultrasound abdomen and repeated stool and urine examinations were normal. A careful review of history revealed that the child had paroxysms of severe periumbilical pain, during which he had palpitations and was cold to the touch. He slept after these attacks. There were no frank convulsions. A diagnosis of abdominal epilepsy was kept in mind. EEG showed an abnormal rhythm indicating epilepsy (polyspike and waves with fast background). The child was put on phenytoin. In spite of being diagnosed as a child with abdominal epilepsy he continued to suffer from abdominal pain for months because father was not convinced that pain is a manifestation of seizure. He restarted anti-ulcer treatment and stopped anticonvulsants. Later when the child suffered from similar complaints he was finally convinced and complied with our regime. The child showed a remarkable response and has been asymptomatic since then (6months). The criteria ${ }^{2}$ for diagnosis of abdominal epilepsy are (i) unexplained periodic or paroxysmal abdominal pain (ii) exclusion of visceral pathology (iii) symptoms of central nervous system problem (iv) abnormal electro-encephalograph and (v) response to anticonvulsant therapy. In abdominal migraine ${ }^{3}$ which mimics abdominal epilepsy, family history of migraine is often present, and the EEG is normal. Stress induced abdominal pain also has a normal EEG. ${ }^{4}$

This case illustrates the problem of cyclic vomiting ${ }^{5}$ and recurrent paroxysmal abdominal pain where several causes of recurrent abdominal pain have to be ruled out. Anxious parents often deny the diagnosis, thinking that abdominal symptoms cannot be due to epilepsy and hence refuse to comply with treatment, as in our case. Sometimes, due to stress of "doctor shopping", child may develop ulcers, which may be temporarily relieved with antacids, thereby reinforcing the fact in parents mind that the pain is due to ulcers. Awareness of possibility of this rare condition in a child with undiagnosed recurrent abdominal pain is needed, both among the doctors and parents. ${ }^{1}$ Lack of faith in treating physician often adds to misery. A patient explanation of the cause of disease by spending time with parents would go a long way to treat this condition satisfactorily and save the child from prolonged suffering.

\author{
Pushpendra Magon \\ Associate Professor \\ Department of pediatrics \\ Vinayaka Missions Medical College \\ Karaikal, Pondicherry, India. \\ E-mail : drpushpendra1969@gmail.com \\ [DOI-10.1007/s12098-010-0141-y]
}

\section{REFERENCES}

1. Zarling EJ. Abdominal epilepsy: An unusual cause of recurrent abdominal pain. Am J Gastroenterol 1984; 79: 687-688.

2. Douglas EF, White PT. Abdominal epilepsy -a reappraisal. I Pediatr 1971; 78: 59-67.

3. Moore MT. Abdominal epilepsy versus "abdominal migraine". Ann Intern Med 1950; 33: 122-133.

4. Singhi PD, Kaur S. Abdominal epilepsy misdiagnosed as psychogenic pain. Postgrad Med J 1988; 64 : 281-282.

5. Wendy G Mitchell, Robert S Greenwood, John A Messenheimer. Abdominal Epilepsy -Cyclic Vomiting as the Major Symptom of Simple Partial Seizures Arch Neurol 1983; 40: 251-252. 